\title{
REVIEW
}

\section{HUMAN AFRICAN TRYPANOSOMIASIS: CURRENT STANDING AND CHALLENGES}

Isabel Theresa Holanda-Freitas ${ }^{1}$, Marli do Carmo Cupertino ${ }^{2}$, Elizária C. dos Santos $^{3}$, Lisa Oliveira ${ }^{4}$, Mauro Geller ${ }^{4}$ and Rodrigo Siqueira-Batista ${ }^{2,5}$

\section{ABSTRACT}

Human African trypanosomiasis (HAT) caused by the protozoan Trypanosoma brucei gambiense and Trypanosoma brucei rhodesiense, and transmitted by the tsetse fly (genus Glossina), affects 36 Sub-Saharan African countries with considerable public health impact. Despite approximately 15,000 infected individuals and 70 million at risk, in recent years the World Health Organization has mentioned removal of HAT from the list of Neglected Tropical Diseases by 2020 , due to the decrease in cases over the last two decades. When untreated, the disease presents high lethality rates and the available treatments are complicated to administer, highly toxic, and do not guarantee cure, especially in the advanced stages of the disease. Further, there is no prospect for vaccine development in the near future. The present review compiles information on the history of the clinical aspects of HAT, as well as its epidemiology, diagnosis, therapy, and prophylaxis, as well as updating information on the current panorama and perspectives regarding the disease.

KEY WORDS: African Trypanosomiasis; neglected diseases; Trypanosoma brucei.

\section{INTRODUCTION}

Human African trypanosomiasis (HAT) or sleeping sickness is a Neglected Tropical Disease (NTD) seriously impacting populations with greater social, cultural, and economic vulnerabilities (Bayão et al., 2019). The disease is caused by subspecies of the protozoa Trypanosoma brucei (highlighting Trypanosoma brucei gambiense, most prevalent in Central and Western Africa - and Trypanosoma brucei rhodesiense, prevalent in East

\footnotetext{
1. Medical School, Universidade Federal de Minas Gerais. Belo Horizonte. Minas Gerais, Brazil.

2. School of Medicine, Faculdade Dinâmica do Vale do Piranga. Ponte Nova, Minas Gerais, Brazil.

3. School of Medicine, Universidade Federal do Vale do Jequitinhonha e Mucuri, Diamantina, Minas Gerais, Brazil.

4. Medical School, Centro Universitário Serra dos Orgãos, Teresópolis, Rio de Janeiro, Brazil.

5. Department of Medicine and Nursing, Universidade Federal de Viçosa, Viçosa, Minas Gerais, Brazil.
}

Corresponding author: Rodrigo Siqueira-Batista, Universidade Federal de Viçosa, Laboratory of Epidemiological and Health Computational Methods in Health, 3rd floor, Room 324, University campus, 36570-900 Viçosa, Minas Gerais, Brazil. E-mail: rsbatista@ufv.br 
Africa), transmitted by the tsetse fly of the genus Glossina (Scarim et al., 2019; Siqueira-Batista et al., 2020). Due to the parasite's ability to cross the blood-brain barrier, neurological and psychiatric impairment are a relevant fact in the clinical course of the disease, increasing its morbidity and mortality profile. Furthermore, outbreaks of sleeping sickness present high lethality rates (Rodgers et al., 2019).

In view of these facts, this review aimed to compile information on the history of the clinical aspects of HAT, as well as its epidemiology, diagnosis, therapy, and prophylaxis, in addition to updating information on the current panorama and prospective scenario of the disease.

\section{ETIOLOGY AND EPIDEMIOLOGY}

Sleeping sickness is caused by a flagelated protozoa of the genus Trypanosoma - phylum Protozoa, sub-phylum Sarcomastigophora, order Kinetoplastida, suborder Trypanosomatina, family Trypanosomatidae, group Salivaria, subgenus Trypanozoon and species Trypanosoma brucei-of which five subspecies stand out: Trypanosoma brucei gambiense and Trypanosoma brucei rhodesiense (greater clinical relevance); Trypanosoma brucei brucei (economic impact due to animal infections), Trypanosoma brucei evansi and Trypanosoma brucei equiperdum (Cupertino et al., 2020; Melhorn, 2008).

The infection cycle (Figure 1) begins when an infected tsetse fly feeds on a healthy individual, injecting metacyclic trypomastigotes under the skin of the vertebrate host. The protozoa multiply by binary fission then spread throughout the body by means of fluids (blood, lymph, and cerebrospinal fluid) where they transform into trypomastigotes. An uninfected tsetse fly becomes infected upon feeding on an infected host, by ingesting the trypomastigote form of the parasite, which migrates to the digestive tract of the vector, transforming into procyclic trypomastigotes which multiply by binary fission. The procyclic trypomastigotes leave the tsetse midgut, migrating to the salivary glands and then transform into epimastigotes, which in turn transform into the human infectious form: metacyclic trypomastigotes. The cycle begins again when the infected tsetse fly feeds again on a healthy host. The parasitic stage in the tsetse fly lasts approximately three weeks (CDC, 2017).

The parasite's cytoskeleton is composed of an interconnected network of microtubules, which adjust and change according to the cell division stage and the various morphologies acquired in the process. As shown in the figure above, in the Trypanosoma brucei life cycle, there are different morphologies and this includes not only remodeling the cytoskeleton but also the internal organelles of the parasite (Sharma et al., 2009). Two main parasite morphologies can be found within the host's bloodstream: slender and stumpy bloodstream forms, which can be differentiated according to cell cycle, morphology and metabolism level. The transition from the slender form to the stumpy form 
occurs at high levels of parasitemia, due to the quorum sensing factor SIF (stumpy induction factor). This SIF factor regulates the parasitic load, as well as favoring the transformation of the parasite to a morphology and metabolism adapted to vector transmission. A single parasite is capable of infecting a tsetse fly, however the slender shape is more efficient due to greater motility until reaching the insect's salivary glands, whereas the stumpy stage presents more resistance to the fly's digestive environment, but a reduced lifetime. (Schuster et al., 2019).

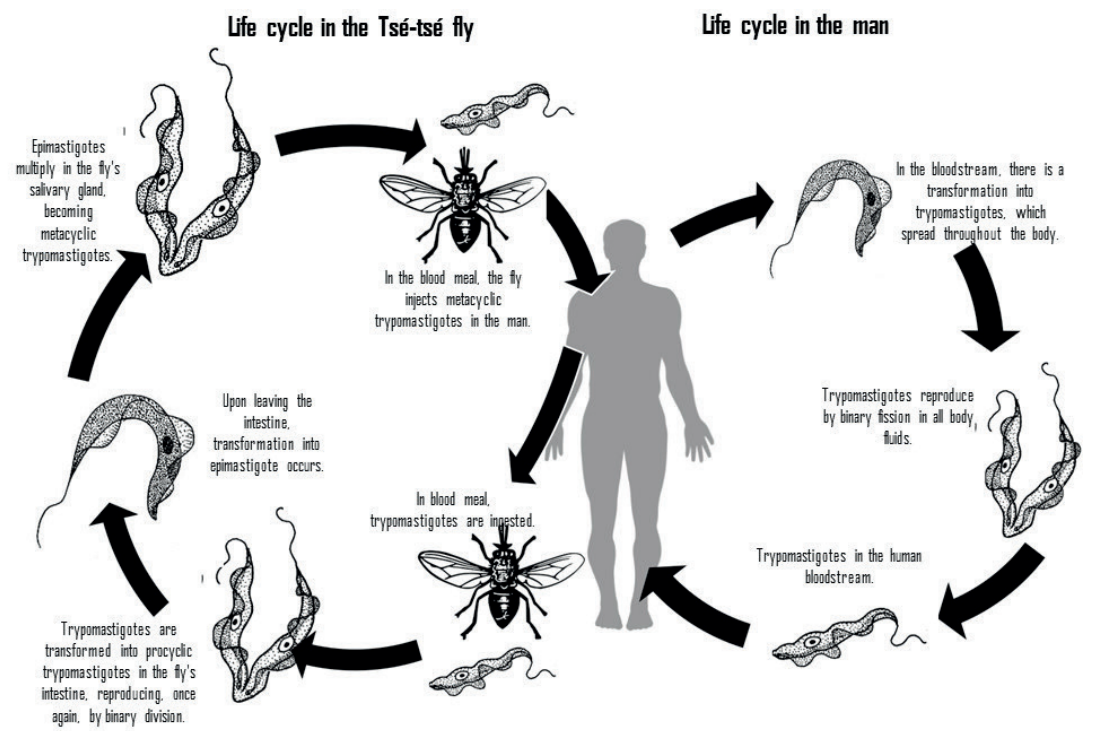

Figure 1. Life cycle of Trypanosoma brucei. Source: adapted from CDC, 2017. Accessed in: http://www.cdc.gov/parasites/sleepingsiclness/biology.html.

Trypanosoma brucei gambiense (88\% of confirmed cases - equivalent to 864 cases) has been seen in West and Central Africa, especially in Angola, Guinea, Mali, Niger, Nigeria, Central African Republic, Gambia, Democratic Republic of Congo, South Sudan and northern Uganda. This disease causes an infection that frequently evolves to chronicity (usually the signs and symptoms arise only months or years after infection). T. brucei rhodesiense $(12 \%$ of registered HAT cases - equivalent to 116 cases) is seen in Eastern and Southern African regions, namely: Malawi, Tanzania, southern Uganda, Zambia and Zimbabwe (WHO, 2020b). 
Within the last 150 years there have been three serious sleeping sickness outbursts in Africa. The first between 1896 and 1906 (Uganda and Democratic Republic of Congo) and the second in 1920 (spread through several African nations). In the 1960s, there were fewer than 5,000 cases of the disease reported throughout the African continent. This led to epidemiological surveillance being neglected for some time, giving rise to the third major and most recent epidemic, lasting from 1970 to 1990. During this period, some countries underwent economic crises, civil wars and deterioration of their healthcare systems, especially in Angola and the Democratic Republic of Congo. The support of the World Health Organization (WHO), national control programs, bilateral cooperation, and the action of non-governmental organizations were necessary to control this last epidemic (Bayão et al., 2019; WHO, 2013).

Given the declining numbers of sleeping sickness cases (Figure 2) - 73\% between 2000 and 2012- the WHO considers HAT may be removed from the list of NTDs by 2020, with interruption of transmission by 2030 (WHO, 2020a). Currently, some African nations including Benin, Botswana, Guinea Bissau, Kenya, Mozambique, Rwanda, and Sierra Leone have had no notifications of new cases in over a decade, therefore it is believed that transmission of the disease has halted in these countries. However, an exact idea of the situation is not possible given the many remote areas and unstable social circumstances that hinder accessibility regarding health surveillance actions (WHO, 2020b).

Below are the numbers of worldwide cases of HAT from 1997 to 2019, caused by the two species and the total number of cases (Figure 2).

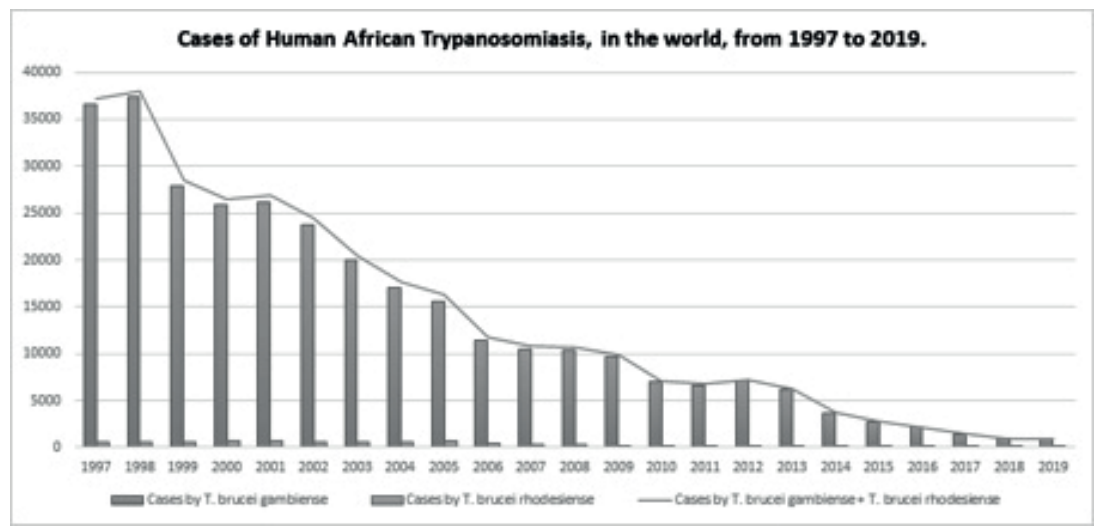

Figure 2. Number of African Human Trypanosomiasis cases, worldwide, from 1997 to 2019. Source: World Health Organization. Data updated until 06/03/2020. Available at: http://apps.who.int/gho/data/node.main. A1635?lang=en. Accessed on 09/11/2020. 


\section{PATHOGENESIS AND IMMUNOLOGICAL ASPECTS}

In relation to the immunological aspects, it is believed that these parasites coevolved with their hosts. In addition, they show morphological, immunological, and metabolic adaptations that favor perpetuation of the parasite life cycle, for example resistance to apolipoprotein A1 (serum protein that triggers death in other members of the Trypanosoma genus).

The periodic antigen alterations found in the protozoan glycoprotein sheath, as well as the incorporation of host antigens in order to evade host immune mechanisms characterize an important parasitic mechanism of pathogenesis. Studies indicate that the parasite presents a single variant surface glycoprotein (VSG), which is continuously altered to evade the action of the immune system of the mammalian host. Some factors are responsible for the success of this survival strategy for T. brucei: 1) almost $20 \%$ of the parasite's genome encodes genes related to VSG, favoring periodic alterations; 2) the VSG genes recombine with each other; 3 ) this characteristic allows the parasite to always be ahead of the host's immune system; and 4) possible antibodies generated against VSGs are quickly rendered unusable due to the genetic exchange rate of the parasite's VSG (Sima et al., 2019).

The role of cytokines in the immune response to the flagellate should be noted, especially that of interferon gamma (IFN- $\gamma$ ) - and its counterregulations mediated by interleukins 10 (IL-10) and 27 (IL-27) - an essential aspect in the balance between immunity and immunopathology ( $\mathrm{Wu}$ et al., 2017). Tumor necrosis factor alpha (TNF- $\alpha$ ) is also able to encompass the immune response adaptation to the production of tissue lesions (Vanwalleghem et al., 2017). This parasite-host interaction explains the long permanence of $T$. bruce i in the individual, as well as the parasitemia fluctuation, corresponding to host immune action, destruction of some percentage of the parasite and its antigenic variation, resulting in intermittent fevers (Krishna et al., 2018). Studies suggest the possibility of using these cytokines as biomarkers, since they are positively regulated in the advanced period of the disease, but further studies are necessary (Kato et al., 2016).

Since the parasites of African human trypanosomiasis move freely in the host's body fluids, it is believed that this generated the need to develop the various survival strategies for immune evasion (Namangala, 2011).

\section{CLINICAL ASPECTS}

The clinical presentation of HAT is variable, depending on the parasite subspecies infecting the host. Accordingly, the clinical characteristics of infection differ in presentation and prognosis. The incubation period of $T$. brucei gambiense infection varies from weeks to months, and virulence 
is moderate, with periodic fluctuation of parasitemia (Pereira et al. 2019). The main lesions are concentrated in the central nervous system, with clear distinction between hemolymphatic and meningoencephalitic phases. Usually, lymphadenomegaly occurs in a lengthy course, lasting from months to a few years. As for T. brucei rhodesiense, the incubation period is shorter compared to T. brucei gambiense, however, it presents high and persistent parasitemia, in addition to elevated virulence (Krafsur \& Maudlin, 2018). In T. brucei rhodesiense infection, there is a fast progression to the meningoencephalic phase and related symptomatology, and lymphadenomegaly is uncommon. Lesions in the central nervous system are more aggressive in the gambiense form, and polyserositis and myocarditis may also occur. In terms of treatment, the protozoan is less sensitive to pharmaceutical products, there are fewer established therapeutic regimens, and the drugs used are toxic with possible fatal side effects (Kirchhoff, 2015). Regardless of the etiological agent, the clinical manifestations can be divided into three main phases: cutaneous, hemolymphatic, and meningoencephalic (Pereira et al. 2019).

Cutaneous phase: after parasite entry, an inoculation chancre can form on the skin, but it may not be visible. The lesion presents phlogistic signs, associated with lymph node enlargement in the affected region, lasting two to three weeks (Streit \& Matsumoto, 2016).

Hemolymphatic phase: marks the start of HAT itself and the symptoms can be unspecific (Kirchhoff, 2015). When present, individuals may present headache, pruritus, anorexia, asthenia, generalized malaise, weight loss, lymphadenopathy (axillary, epitrochlear, supraclavicular and cervical lymph node chains) and the Kerandel sign (profound hyperesthesia, with delayed pain sensation following digitopression of soft tissues) (Chappuis et al., 2005). Laboratory investigation reveals anemia, monocytosis, increased blood sedimentation rate (due to the inflammatory processes disseminated throughout the host organism) and altered plasma protein profile (hypoalbuminemia and hypergammaglobulinemia) (Kirchhoff 2015, Streit \& Matsumoto, 2016).

Meningoencephalic phase: especially in the Eastern form of the disease, in which neuropsychological alterations are triggered. The milestone of the meningoencephalic period corresponds to the parasite's entry into the central nervous system. Neurological manifestations occur together with the neuroinflammatory response. Studies indicate that Trypanosoma brucei infection generates a continuous and progressive deterioration of the blood-brain barrier, impairing function, and that enzymes in the parasite are responsible for facilitating this process and invasion of the CNS (Kennedy \& Rodgers, 2019). Main findings are: headache, insomnia, adynamia, significant weight loss (including cachexia), mood swings, limb and eyelid tremors, gait disturbances resulting from cerebellar ataxia, involuntary movements of the limbs and trunk - choreiform, athetoid, or oscillatory -, muscular hypertonia or hypotonia, fasciculation, akinesia, speech disorders, 
as well as focal neurological alterations in cranial nerve pairs and disorders compatible with subacute meningoencephalitis. Although not very common, generalized convulsions may also occur, more likely in children and in cases of encephalopathy induced by the drug melasorprol (Shankar-Hari et al., 2016; Singer et al., 2016). The psychiatric findings correlate especially with emotional instability, attention deficit, and apathy (Krishna et al., 2018). This period is characterized by hypersomnia. However, although this disturbance is very typical of HAT (especially in the gambiense form), this characteristic is not pathognomonic of the disease (Rijo-Ferreira et al., 2018). Neuropsychiatric manifestations result from direct damage to the central nervous system. While the occurrence of myelitis, peripheral and optic neuropathy are caused by inflammatory processes (Berkowitz et al., 2015).

\section{DIAGNOSIS AND THERAPEUTIC TARGETS}

\section{Laboratory Diagnosis}

The approach to HAT presents an important challenge since diagnostic methods can be limited regarding precision, sensitivity, and cost (WHO, 2020a). It is important to consider compatible clinical manifestations, especially with fever (hemolymphatic phase), or neuropsychiatric symptoms (meningoencephalitic phase). In addition, epidemiological findings such as exposure history due to residence or travel in endemic areas must be investigated, given the limited geographic distribution of the parasite (Aksoy et al., 2017; WHO, 2020b). In suspect cases, laboratory investigation should be carried out to identify the protozoan in the blood, lymph, lymph node or chancre aspirate, or cerebrospinal fluid (Aksoy et al., 2017). Early diagnosis is important to prevent disease progression to the meningoencephalitic phase and to control the dissemination of Trypanosoma brucei to tsetse flies, aiding in the progressive mitigation of the disease (Aksoy et al., 2017; WHO, 2020b).

T. brucei rhodesiense and T. brucei gambiense share identical morphological aspects, but geographic exposure and chronicity of manifestations are usually utilized to determine etiology. Determination of the disease phase (hemolymphatic or meningoencephalitic phase) is confirmed by examination of cerebrospinal fluid, which should always be performed in cases of suspected HAT, even in the absence of neurological complaints, considering the result of this exam is crucial to therapeutic conduct (Aksoy et al., 2017). The (i) serological, (ii) parasitological and (iii) immunochromatographic tests for the diagnostic evaluation of HAT will be described below.

1. Serum assays. Screening tests are the first approach for asymptomatic patients. The most widely used in the screening of T. brucei gambiense infection is the Card Agglutination Test for Trypanosomiasis (CATT) (Solomon et al., 2016). CATT testing is based on agglutination of lyophilized Trypanosoma 
in the presence of a specific antibody; sensitivity varies between $94-98 \%$. Specificity depends on the biological fluid used - blood or plasma, and crossreactions may occur with trypanosomal antibodies from non-pathogenic animals or the occurrence of previous infection. It is a simple test with results within 10 minutes, and if positive (presence of visible protozoan agglutination), the patient is referred to lymph node aspiration or blood smear analysis, in order to identify the etiologic agent (Krishna et al., 2018). Despite not being an adequate test to confirm a diagnosis (especially T. brucei rhodesiense), it is important to guide the disease approach and epidemiological research (Krishna et al., 2018). A new rapid diagnostic test was developed in partnership with the Foundation for Innovative New Diagnostics (FIND) - with favorable outcomes when compared to CATT. Other tests to detect anti-trypanosomal antibodies in CSF have been developed, but lack satisfactory sensitivity (Krishna et al., 2018). Although there is no test with $100 \%$ sensitivity, in some cases diagnostic confirmation must rely on the triad of (i) clinical picture, (ii) epidemiological context, and (iii) positive CATT test result (Aksoy et al., 2017; Kazumba et al., 2018). Antibody detection samples have no clinical use since seroconversion occurs after the onset of symptoms, although the agglutination test for T. b. gambiense is useful in screening programs to identify candidates for microscopic analysis.

2. Parasitological assays. These assays detect the parasite in blood (smear and concentration method), CSF (by direct visualization of parasite via microscopy), or lymph node, bone marrow, or inoculation chancre aspirates (Wamboga et al., 2017). In exams using blood samples, sensitivity increases with concentration techniques such as the quantitative buffy coat (QBC) technique, which uses centrifugation and fluorescent dye, and the mini Anion Exchange Centrifugation Technique (mAECT), a technique employing an anion exchange column and blood filtration through a parasite-permeable resin (Kazumba et al., 2018). Polymerase chain reaction (PCR) is a tool used mostly for research, it is not standardized and therefore is also not used in clinical settings (Kennedy, 2013; Büscher et al., 2017). Another diagnostic approach described in the literature is xenodiagnosis. This method is based on exposure of possibly infected material to uninfected flies of the Glossina genus. After exposure, the presence of the etiological agent in the flies is analyzed. This technique has greater applicability in scientific research (Büscher et al., 2018).

3. Rapid diagnostic test for HAT (immunochromatography). There are two types of immunochromatographic tests on the market, the first being the rapid diagnostic test (RDT) SD BIOLINE ${ }^{\circledR}$ HAT RDT and the second the HAT Sero-K-Set ${ }^{\circ}$ test, both first generation and considered lateral flow immunochromatography tests. Both RDT tests qualitatively screen host antibodies to variable surface glycoprotein (VSG) LiTat 1.3 and/or LiTat 1.5 expressed by $T$. $b$. gambiense. The SD BIOLINE® HAT RDT presents $92 \%$ sensitivity (95\% confidence interval [CI] of $86.1-95.5 \%)$ and $97 \%$ specificity, while HAT Sero-K-Set screens for for LiTat 1.3 with $100 \%$ sensitivity $(95 \%$ CI: 
67.6-100.0) and $97.0 \%$ specificity. HAT cases have shown waves of parasitemia with varying variable antigen types (VATs) during infection, therefore RDTs are easily accessible test options. Both tests can use plasma or whole blood samples, last 15 to 20 minutes and are performed according to the manufacturer's instructions (Lumbala et al., 2017, Boelaert et al., 2018).

Regarding the diagnostic options, there are still two other tools: 1) repetitive insertion mobile element (RIME) for LAMP and 2) isothermal nucleic acid sequence-based amplification (NASBA) assays.

Nucleic acid sequence-based amplification (NASBA) is a transcriptionbased amplification system specifically designed for the detection of RNA targets. It doesn't require expensive equipments and can be used in a clinical scenario with higher sensitivity than RT-PCR for detection of the pathogen. Studies emphasize that in the future NASBA tests may be used as routine diagnostic procedures. Meanwhile, NASBA lacks reproducibility (Fakruddin et al., 2012).

RIME-LAMP is a method in which DNA is amplified with higher sensitivity and speed under isothermal conditions. "Findings support that LAMP is comparable to PCR when used on CSF samples in the field, an important tool for clinical decision making. Results suggest repeatability is low in animals with low parasitaemia" (Gummery et al., 2020). "LAMP may be useful to monitor emerging HAT foci or to test travelers returning from countries where HAT is endemic" (Matovu et al., 2010).

\section{Central Nervous System (CNS) Imaging and electroencephalographic findings}

The use of CNS imaging such as computerized tomography and magnetic resonance imaging, is limited because these detect alterations only in severe cases in the nervous phase of the disease (Wengert et al., 2014; SiqueiraBatista et al., 2020). Patients with neurological impairment may also present electroencephalographic (EEG) alterations, such as slow wave oscillations (delta waves); however, EEGs are rarely performed in endemic areas (Büscher et al., 2017).

\section{Therapeutic aspects}

HAT treatment remains a challenge since the available drug therapy alternatives present high toxicity, poor organic tolerability, and low efficacy. These factors, if added to the pharmaceutical industry's lack of interest in designing new drugs, hamper the clinical approach to this disease (FAO, 2017; WHO, 2020b). For a detailed review of the therapeutic schemes and targets for HAT as well as their mechanisms of action and resistance, refer to Koning (2020). The general summary of the therapeutic aspects of HAT is shown in table 1. 
Table 1. Therapeutic targets used in context of the Human African Trypanosomiasis.

\begin{tabular}{|c|c|}
\hline DRUG & COMMENTS \\
\hline Fexinidazole & $\begin{array}{l}\text { Action against } T \text {. brucei gambiense (first and non-severe } \\
\text { second phase). } \\
\text { Efficacy and safety proven by clinical studies led by the } \\
\text { Drugs for Neglected Diseases Initiative (DNDi). } \\
\text { Creates reactive amine species that are indirectly toxic } \\
\text { and mutagenic to trypanosomes (Bahia et al., 2012; } \\
\text { Deeks, 2019). }\end{array}$ \\
\hline $\begin{array}{l}\text { Eflornithine } \\
\text { (DFMO) }\end{array}$ & $\begin{array}{l}\text { Irreversible inhibitor of the enzyme ornithine } \\
\text { decarboxylase with antiparasitic activity against } \\
\text { Trypanosoma brucei gambiense (including } \\
\text { meningoencephalic) infections. } \\
\text { Blocks the active site of the enzyme ornithine } \\
\text { decarboxylase by deactivating it, thus depriving the } \\
\text { trypanosome of polyamine synthesis. The resulting } \\
\text { increase in S-adenosylmethionine levels and methylation } \\
\text { of proteins, nucleic acids and other components is } \\
\text { harmful to the parasite (Etet \& Mahomoodally, 2012). } \\
\text { Ornithine decarboxylase is also necessary for the } \\
\text { synthesis of parasite DNA and RNA. }\end{array}$ \\
\hline Melarsoprol & $\begin{array}{l}\text { Arsenic-based drugs were the very first treatments } \\
\text { against sleeping sickness used for treatment of the } \\
\text { Rhodesian form and second-choice drug in the treatment } \\
\text { of Gambian trypanosomiasis. } \\
\text { Enters the parasite through purine transporters (that are } \\
\text { quite developed in the species), acting as a competitive } \\
\text { compound to the purine site in the carrier protein (Etet \& } \\
\text { Mahomoodally, 2012). It is an organoarsenic compound } \\
\text { which inhibits parasite glycolysis (Barrett et al., 2007). }\end{array}$ \\
\hline Nifurtimox & $\begin{array}{l}\text { Emerged to replace melarsoprol for late-stage HAT. } \\
\text { Action on T. brucei gambiense infection and can be used } \\
\text { in combination with eflornithine or melarsoprol to reduce } \\
\text { the number of relapses in melarsoprol monotherapy. } \\
\text { Is reduced by the type II nitro-reductase enzyme, } \\
\text { generating superoxide anions and nitro anion radicals } \\
\text { that may have parasite-killing activity mediated by } \\
\text { induction of oxidative stress (Hall et al., 2011). }\end{array}$ \\
\hline
\end{tabular}




\begin{tabular}{|l|l|}
\hline \multirow{5}{*}{ Pentamidine } & $\begin{array}{l}\text { May interfere with DNA biosynthesis. Good action } \\
\text { against } T \text {. brucei gambiense, but poor action on T. brucei } \\
\text { rhodesiense. Lacks activity in the meningoencephalic } \\
\text { phase of infection. } \\
\text { A cationic compound whose main action is to interfere } \\
\text { in the aerobic and anaerobic respiration of the } \\
\text { microorganism. It can interact with DNA or nucleotides } \\
\text { and their derivatives, inhibiting enzymes, interfering in } \\
\text { the function or uptake of polyamines, and impairing the } \\
\text { synthesis of DNA, RNA, proteins and phospholipids } \\
\text { (Costa, 1993). }\end{array}$ \\
\hline Suramin & $\begin{array}{l}\text { Polysulfonated polyaromatic symmetrical urea with } \\
\text { trypanocidal activity. Action against both T. brucei } \\
\text { rhodesiense and T. brucei gambiense (does not act in the } \\
\text { meningoencephalic phase). } \\
\text { Causes inhibition of several enzymes, endocytosis of } \\
\text { some molecules, binding of LDL to specific receptors } \\
\text { and interferes with cell division. It can also cause changes } \\
\text { in the cytoskeleton during intracellular development, } \\
\text { promoting changes in the flagellum and its functionality } \\
\text { (Bisaggio et al., 2006). }\end{array}$ \\
\hline
\end{tabular}

Source: Adapted from: Siqueira-Batista et al. (2003); Fairlamb \& Horn (2018); Kazumba et al. (2018); Koning (2020); WHO (2020a); Mesu et al. (2018).

Treatment of infected pregnant women can present a serious risk. Pentamidine can be administered after the first semester of gestation, and nifurtimox, eflornithine, and melarsoprol are not indicated unless the patient is in the meningoencephalic phase of the disease and there is more benefit in immediate drug treatment than in waiting for the end of the pregnancy (Krishna et al., 2018).

CSF analysis is mandatory in all patients prior to the establishment of the therapeutic regimen, to confirm CNS involvement. If CSF is normal (and in the absence of neuropsychiatric symptomatology), suramin or pentamidine should be used (except in cases of T. brucei rhodesiense infection). However, if CSF is altered, either by the presence of the parasite or atypical protein or cell patterns, melasorprol associated with suramin should be used in Eastern trypanosomiasis, or eflornithine in Western trypanosomiasis (Giordani et al., 2016; WHO, 2020b). 
After adequate treatment, it is possible to reach a cure in up to $95 \%$ of cases in the hemolymphatic phase and $90 \%$ of cases in the meningoencephalic phase. Unfortunately, treatment failure in some areas of Africa can reach up to $30 \%$ of the most severe cases treated with melarsoprol. Cure control is conducted through CSF evaluation at three-month intervals for one year for the Eastern form of the disease, or every six months for two years, for the Western form of the disease (Goupil \& Mckerrow, 2014; Giordani et al., 2016; WHO, 2020b). Therapeutic failure is determined in the recurrence of CSF changes or neurological symptoms, and treatment is reinitiated with drugs in association with nifurtimox or, in the case of the Western form, with mandatory use of eflornithine (Giordani et al., 2016).

\section{PREVENTION AND CONTROL}

There are currently no vaccines or prophylactic drugs for HAT and the preventive measures basically aim to avoid or reduce contact with infected tsetse flies. It is also important to avoid moving through endemic areas. The use of insect repellents, protective screens, and curtains are also extremely useful measures (Giordani et al., 2016; Pereira et al., 2017). To prevent new cases of trypanosomiasis the detection of new cases of infection is crucial, since these individuals are parasite reservoirs and may potentially infect all tsetse flies that they come into contact with (FAO, 2017; WHO, 2020a). Besides, naturally infected animals are also possible reservoirs for the Gambian form and must be investigated (Büscher et al., 2018). Below is a summary of the main prevention and control measures (CDC, 2017; FAO, 2017; Medlock et al., 2013; Wamwiri et al., 2013; WHO, 2020b):

(1) early detection of infected individuals, with clinical evaluation and screening tests for at-risk populations, with attention to asymptomatic cases (CDC, 2017; WHO, 2020b);

(2) vector control through traps, individual protection, and mass reduction of the vector community of symbiotic bacteria of the genera Wolbachia, Sodalis or Wigglesworthia, essential to fly survival. The bacteria genus Wigglesworthia and Sodalis reside in the intestine in close association with the protozoa of the genus Trypanosoma and may influence the establishment and development of parasitic infections in the midgut (Wamwiri et al., 2013). Wolbachia was seen to induce reproductive effects in the infected tsetse fly. Paratransgenesis associated with tsetse fly control can also be useful (Medlock et al., 2013).

(3) health education, covering all inhabitants of at-risk areas and travelers (CDC, 2017; WHO, 2020b). 


\section{PERSPECTIVES}

Despite the social vulnerability and fragility of the political structures impacting the populations affected by HAT, advances in control and reduced disease incidence have been noted, and this has only been possible thanks to the work of governmental and non-governmental organizations and the WHO (CDC, 2017; FAO, 2017; Holanda-Freitas et al., 2018; WHO, 2020a). Furthermore, the removal of HAT from the list of NTDs by 2020 is under consideration (WHO, 2020a). In addition, another major scientific advance is the completion of the genome sequencing of the Glossina morsitans morsitans fly and five additional vector species (Watanabe et al., 2014). This will enable the development of better and more effective biological control methods, either by eliminating the insects, as recently occurred in Zanzibar (Wamwiri et al., 2013), or by reducing vector density through additional tools such as specific traps, sprays, and sterilization techniques. Furthermore, the development of new drugs with improved toxicity profiles and greater effectiveness is of fundamental importance.

\section{CONFLICT OF INTEREST}

The authors declare that they have no conflicts of interest.

\section{REFERENCES}

1. Aksoy S, Buscher P, Lehane M, Solano P, Van Den Abbeele J. Human African trypanosomiasis control: achievements and challenges. PLoS Negl Trop Dis 11: e0005454, 2017.

2. Bahia MT, Andrade IM, Martins TAF, Nascimento AFS, Diniz LF, Caldas IS, Ribeiro I. Fexinidazole: a potential new drug candidate for Chagas Disease. PLoS Negl Trop Dis 6: e1870, 2012.

3. Barrett MP, Boykin DW, Brun R, Tidwell RR. Human African trypanosomiasis: pharmacological re-engagement with a neglected disease. Br J Pharmacol 152: 1155-1171, 2007.

4. Bayão TS, Cupertino MC, Gomes AP, Siqueira-Batista R. Fexinidazole and Human African Trypanosomiasis: good news for this important neglected tropical disease. Rev Soc Bras Med Trop 52: e20190176, 2019.

5. Berkowitz AL, Raibagkar P, Pritt BS, Mateen FJ. Neurologic manifestations of the neglected tropical diseases. J Neurol Sci 349: 20-32, 2015.

6. Bisaggio DFR, Campanati L, Pinto RCV, Souto-Padrón T. Effect of suramin on trypomastigote forms of Trypanosoma cruzi: changes on cell motility and on the ultrastructure of the flagellumcell body attachment region. Acta Trop 98: 162-175, 2006.

7. Boelaert M, Mukendi D, Bottieau E, Kalo Lilo JR, Verdonck K, Minikulu L, Lutumba P. A Phase III diagnostic accuracy study of a rapid diagnostic test for diagnosis of second-stage human African trypanosomiasis in the Democratic Republic of the Congo. EBioMedicine 27: 11-17, 2018. 
8. Büscher P, Cecchi G, Jamonneau V, Priotto G. Human African trypanosomiasis. Lancet 390: 2397-2409, 2017.

9. Büscher P, Bart JM, Boelaert M, Bucheton B, Cecchi G, Chitnis N, Courtin D, Figueiredo LM, Franco JR, Grébaut P, Hasker E, Ilboudo H, Jamonneau V, Koffi M, Lejon V, MacLeod A, Masumu J, Matovu E, Mattioli R, Noyes H, Picado A, Rock KS, Rotureau B, Simo G, Thévenon S, Trindade S, Truc P, Reet NV. Do Cryptic reservoirs threaten Gambiense-sleeping sickness elimination? Trends Parasitol 34: 197-207, 2018.

10. CDC. Centers for Diseases Control and Prevention. Parasites-African Trypanosomiasis (also known as Sleeping Sickness). 2017. Available in: https://www.cdc.gov/parasites/ sleepingsickness/ Accessed in: 03/03/2020.

11. Chappuis F, Loutan L, Simarro P, Lejon V, Büscher P. Options for field diagnosis of human african trypanosomiasis. Clin Microbiol Rev 18: 133-146, 2005.

12. Costa JML. O uso clínico das pentamidinas com especial referência nas leishmanioses. Acta Amaz 23: 163-172, 1993.

13. Cupertino MC, Bayão T, Siqueira-Batista R. Tripanossomíases Humanas Atípicas. In: Siqueira-Batista R, Gomes AP, Santana LA, Santos S. Parasitologia: fundamentos e prática clínica. Rio de Janeiro, Guanabara Koogan, 2020. Vol. 1. p. 285-290.

14. Deeks ED. Fexinidazole: First Global Approval. Drugs 79: 215-220, 2019.

15. Etet PFS, Mahomoodally MF. New insights in staging and chemotherapy of African trypanosomiasis and possible contribution of medicinal plants. Scientific World J 2012: 1-16, 2012.

16. Fairlamb AH, Horn D. Melarsoprol resistance in African Trypanosomiasis. Trends Parasitol 34: 481-492, 2018.

17. Fakruddin MD, Mazumdar RM, Chowdhury A, Mannan SB. Nucleic acid sequence based amplification (NASBA)-prospects and applications. Int J Life Sci Pharma Res 2: 106-121, 2012.

18. FAO (Food and Agriculture Organization) of the United Nations. 2017. Programme Against African Trypanosomiasis: PAAT Maps. Available in: http://www.fao.org/ag/againfo/ programmes/en/paat/maps.html. Accessed in: 03/03/2020.

19. Giordani F, Morrison LJ, Rowan TG, De Koning HP, Barrett MP. The animal trypanosomiases and their chemotherapy: a review. Parasitology 143: 1862-1889, 2016.

20. Goupil LS, McKerrow JH. Introduction: drug discovery and development for neglected diseases. Chem Rev 114: 11131-11137, 2014.

21. Gummery L, Jallow S, Raftery AG, Bennet E, Rodgers J, Sutton DGM. Comparison of loopmediated isothermal amplification (LAMP) and PCR for the diagnosis of infection with Trypanosoma brucei ssp. in equids in The Gambia. PLoS One 15: e237187, 2020.

22. Hall BS, Bot C, Wilkinson SR. Nifurtimox activation by trypanosomal type I nitroreductases generates cytotoxic nitrile metabolites. J Biol Chem 286: 13088-13095, 2011.

23. Holanda-Freitas IT, Bayão TS, Cupertino MC, Cardoso dos Santos E, Siqueira-Batista R. The human African trypanosomiasis control perspectives in the world: advances and challenges. Proceedings of XXXIV Annual Meeting of the Brazilian Society of Protozoology / XLV Annual Meeting on Basic Research in Chagas Disease v. 1. p. 99, 2018. Available in: https://sbpz.org. br/wp-content/uploads/2018/11/06-hp-53-ATE-116-2018.pdf. Accessed in: 08/10/2019.

24. Kato CD, Matovu E, Mugasa CM, Nanteza A, Alibu VP. The role of cytokines in the pathogenesis and tagging of Trypanosoma brucei rhodesiense sleeping sickness. Allergy Asthma Clin Immunol 12: 4, 2016.

25. Kazumba LM, Kaka JT, Ngoyi DM, Tshala-Katumbay D. Mortality trends and risk factors in advanced stage-2 Human African Trypanosomiasis: A critical appraisal of 23 years of experience in the Democratic Republic of Congo. PLoS Negl Trop Dis 12: e0006504, 2018.

26. Kennedy PGE. Clinical features, diagnosis, and treatment of human African trypanosomiasis (sleeping sickness). Lancet Neurol 12: 186-194, 2013. 
27. Kennedy PGE, Rodgers J. Clinical and Neuropathogenetic Aspects of Human African Trypanosomiasis. Front Immunol 10: 39, 2019.

28. Kirchhoff LV. Agents of African Trypanosomiasis (Sleeping Sickness). In: Bennett JE, Dolin R, Blaser MJ (ed). Mandell, Douglas, and Bennett's Principles and Practice of Infectious Diseases. 8 ed. Elsevier Saunders: Philadelphia, 2015. p.3116-3121.

29. Koning HPD. The drugs of Sleeping Sickness: their mechanisms of action and resistance, and a brief history. Trop Med Infect Dis 5: 14, 2020.

30. Krafsur ES, Maudlin I. Tsetse fly evolution, genetics and the trypanosomiases. -A review. Infect Genet Evol 64: 185-206, 2018.

31. Krishna S, Weller PF, Stich A, Baron EL. African trypanosomiasis: clinical manifestations, diagnosis, and treatment. UpToDate, 2018. Available in: https://www.uptodate.com/contents/ african-trypanosomiasis-clinical-manifestations-diagnosis-and-treatment. Accessed in: $02 / 02 / 2020$.

32. Lumbala C, Bessell PR, Lutumba P, Baloji S, Biéler S, Ndung'u JM. Performance of the SD BIOLINE $®$ HAT rapid test in various diagnostic algorithms for gambiense human African trypanosomiasis in the Democratic Republic of the Congo. PLoS One 12: e0180555, 2017.

33. Matovu E, Kuepfer I, Boobo A, Kibona S, Burri C. Comparative detection of trypanosomal DNA by loop-mediated isothermal amplification and PCR from flinders technology associates cards spotted with patient blood. J Clin Microbiol 48: 2087-2090, 2010.

34. Medlock J, Atkins KE, Thomas DN, Aksoy S, Galvani AP. Evaluating Paratransgenesis as a Potential Control Strategy for African Trypanosomiasis. PLoS Negl Trop Dis 7: e2374, 2013.

35. Melhorn H. Trypanosoma. In: Mehlhorn H (eds). Encyclopedia of parasitology. SpringerVerlag Berlin Heidelberg: New York, 2008. 3084p.

36. Mesu VKBK, Kalonji WM, Bardonneau C, Mordt OV, Blesson S, Simon F, Delhomme S, Bernhard S, Kuziena W, Fina Lubaki JPF, Vuvu SL, Ngima PN, Mbembo HM, Ilunga M, Bonama AK, Heradi JA, Solomo JLL, Mandula G, Badibabi LK, Dama FR, Lukula PK, Tete DN, Lumbala C, Scherrer B, Strub-Wourgaft N, Tarral A. Oral fexinidazole for late-stage African Trypanosoma brucei gambiense trypanosomiasis: a pivotal multicentre, randomised, non-inferiority trial. Lancet 391: 144-154, 2018.

37. Namangala B. How the African trypanosomes evade host immune killing. Parasite Immunol 33: 430-437, 2011.

38. Pereira RM, Greco GMZ, Moreira AM, Chagas PF, Caldas IS, Gonçalves RV, Novaes RD. Applicability of plant-based products in the treatment of Trypanosoma cruzi and Trypanosoma brucei infections: a systematic review of preclinical in vivo evidence. Parasitology 144: 12751287, 2017.

39. Pereira SS, Trindade S, Mariana DN, Figueiredo LM. Tissue tropism in parasitic diseases. Open Biol 9: 190036, 2019.

40. Rijo-Ferreira F, Carvalho T, Afonso C, Sanches-Vaz M, Costa RM, Figueiredo LM, Takahashi JS. Sleeping sickness is a circadian disorder. Nat Commun 9: 62, 2018.

41. Rodgers J, Steiner I, Peter G, Kennedy E. Generation of neuroinflammation in human African trypanosomiasis. Neurol Neuroimmunol Neuroinflamm 6: e610, 2019.

42. Scarim CB, Jordana DH, Machado MGM, Ferreira CMR, Dos Santos JL, Chung MC, Thiazole, thio and semicarbazone derivatives against tropical infective diseases: Chagas disease, human African trypanosomiasis (HAT), leishmaniasis, and malaria. Eur J Med Chem 162: 378-395, 2019.

43. Schuster S, Subota I, Lisack J, Zimmermann H, Reuter C, Morriswood B, Engstler M. A modification to the life cycle of the parasite Trypanosoma brucei. bioRxiv 2019: 1-29, 2019. 
44. Shankar-Hari M, Phillips GS, Levy ML, Seymour CW, Liu VX, Deutschman CS, Angus DC, Rubenfeld GD, Singer M. Developing a New Definition and Assessing New Clinical Criteria for Septic Shock: For the Third International Consensus Definitions for Sepsis and Septic Shock (Sepsis-3). JAMA 315: 775-787, 2016.

45. Sharma R, Gluenz E, Peacock L, Gibson W, Gull K, Carrington M. The heart of darkness: growth and form of Trypanosoma brucei in the tsetse fly. Trends Parasitol 25: 517-524, 2009.

46. Sima N, Emilia Jane McLaughlin EJ, Hutchinson S, Glover L. Escaping the immune system by DNA repair and recombination in African trypanosomes. Open Biol 9: 190182, 2019.

47. Singer M, Deutschman CS, Seymour CW, Shankar-Hari M, Annane D, Bauer M, Bellomo R, Bernard GR, Chiche JD, Coopersmith CM, Hotchkiss RS, Levy MM, Marshall JC, Martin GS, Opal SM, Rubenfeld GD, Poll TVD, Vincent JL, Angus DC. The third international consensus definitions for sepsis and septic shock (Sepsis-3). JAMA 315: 801-810, 2016.

48. Siqueira-Batista R, Igreja RP, Albajar Viñas P. Doença do sono (tripanossomíase humana africana). In: Siqueira-Batista R, Gomes AP, Silva Santos S, Almeida LC, Figueiredo CES, Bedoya Pacheco SJ. Manual de Infectologia. Rio de Janeiro: Revinter, 2003. p.370-374.

49. Siqueira-Batista R, Pinto LBGF, Monteiro BG, Cupertino MC, Fonseca MS. Tripanossomíase Humana Africana/ doença do sono. In: Siqueira-Batista R, Gomes AP, Santana LA, Silva Santos S. Parasitologia: fundamentos e prática clínica. Rio de Janeiro: Guanabara Koogan, 2020. p.275-284.

50. Solomon NK, Idris LA, Oluseyi Oluyinka O. Silent Human Trypanosoma brucei gambiense: infections around the Old Gboko Sleeping Sickness Focus in Nigeria. J Parasitol Res 2016: 2656121, 2016.

51. Streit JA, Matsumoto E. African Trypanosomiasis. N Engl J Med 375: 2380, 2016.

52. Vanwalleghem G, Morias Y, Beschin A, Szymkowski DE, Pays E. Trypanosoma brucei growth control by TNF in mammalian host is independent of the soluble form of the cytokine. Sci Rep 7: 6165, 2017.

53. Wamboga C, Matovu E, Bessell PR, Picado A, Biéler S, Ndung'u JM. Enhanced passive screening and diagnosis for gambiense human African trypanosomiasis in north-western Uganda - Moving towards elimination. PLoS One 12: e0186429, 2017.

54. Wamwiri FN, Alam U, Thande PC, Aksoy E, Ngure RM, Aksoy S, Ouma JO, Murilla GA. Wolbachia, Sodalis and trypanosome co-infections in natural populations of Glossina austeni and Glossina pallidipes. Parasit Vectors 6: 232, 2013.

55. Watanabe J, Hattori M, Berriman M, Lehane MJ, Hall N, Solano P, Aksoy S and collaborators. Genome sequence of the tsetse fly (Glossina morsitans): vector of African trypanosomiasis. Science 344: 380-386, 2014.

56. Wengert O, Kopp M, Siebert E, Stenzel W, Hegasy G, Suttorp N, Stich A, Zoller T. Human African trypanosomiasis with 7-year incubation period: clinical, laboratory and neuroimaging findings. Parasitol Int 63: 557-560, 2014.

57. World Health Organization. Sustaining the drive to overcome the global impact of Neglected Tropical Diseases: second WHO report on neglected tropical diseases, 2013. Available in: https://www.who.int/neglected_diseases/9789241564540/en/ Accessed in: 12/09/2019.

58. World Health Organization. The world gears-up to eliminate sleeping sickness by 2020a. Available in: http:/www.who.int/trypanosomiasis_african/news/The-world-gears-up-toeliminate-HAT-2020/en/ Accessed in: 03/03/2020.

59. World Health Organization. Trypanosomiasis, human African (sleeping sickness). Updated February 2020b. Available in: https:/www.who.int/en/news-room/fact-sheets/detail/ trypanosomiasis-human-african-(sleeping-sickness) Accessed in: 09/11/2020.

60. Wu H, Liu G, Shi M. Interferon Gamma in African Trypanosome Infections: Friends or Foes? Front Immunol 8:1105, 2017. 